\title{
PENERAPAN SANITASI TOTAL BERBASIS MASYARAKAT (STBM) PILAR 1 STOP BUANG AIR BESAR SEMBARANGAN (STOP BABS) DENGAN KEJADIAN PENYAKIT DIARE DI KELURAHAN LAKKANG KECAMATAN TALLO KOTA MAKASSAR Syamsuddin $\mathrm{S}^{1}$ dan Asriani ${ }^{2}$ \\ 1.2Jurusan Kesehatan Lingkungan Politeknik Kesehatan Kemenkes Makassar syam.kesling@gmail.com
}

\begin{abstract}
Community Based Total Sanitation (STBM) is a government program effort that is not open defecation (BAB), washing hands with soap, managing drinking water, and food, managing garbage, and household water waste. The purpose of this study was to determine the implementation of Community-Based Total Sanitation (STBM) Pillar 1: Open Defecation (Stop Open Defecation) With Diarrhea Disease in Lakkang Village, Tallo District, Makassar City. This type of research studies with a descriptive approach by analyzing the description of settlement conditions with the application of the STBM program with a population of 252 households and a sample of 155 households. The results of the Latrine ownership access study show that almost all residents have defecated in the Latrine and implemented the STBM Pillar 1 Stop BABS program which is 141 households with a percentage of 91\%. sanitation facility ownership of the STBM Program is 93 households, 60\%, Numpang 35 households, 23\%, Public facilities 27 households, 17\%. Private ownership is 60\%. Cemplung 1 unit of 15 families as much as 9\% and Goose Neck 139 units of 139 families as much as 90\%. Condition of facilities Good 13\% and 54\% are still lacking and not defecating in Jamban $61 \mathrm{HH} 39 \%$, and increasing $93 \mathrm{HH} \mathrm{60 \% ,99 \%} \mathrm{have} \mathrm{not} \mathrm{defecated} \mathrm{just}$ anywhere. Suffer Diarrhea $45 \mathrm{HH} 29 \%$, no diarrhea $110 \mathrm{HH}$ or $71 \%$. The conclusion in this study is that $99 \%$ of residents have not defecated in any place although not 100\% ODF, the level of diarrhea sufferers have decreased and for the application of the first pillar of STBM namely Stop BABS it is stated that there is a change in the conditions of sanitation access STBM program specifically about pillar 1 Stop BABS.
\end{abstract}

Keywords: CLTS ,ODF.

\section{ABSTRAK}

Sanitasi Total Berbasis Masyarakat (STBM) merupakan upaya program pemerintah yaitu tidak buang air besar (BAB) sembarangan, cuci tangan pakai sabun, mengelola air minum dan makanan, mengelola sampah, dan limbah air rumah tangga. Tujuan penelitian Untuk Mengetahui Penerapan Sanitasi Total Berbasis Masyarakat (STBM) Pilar 1 Stop Buang Air Besar Sembarangan (Stop BABS) Dengan Kejadian Penyakit Diare Di Kelurahan Lakkang Kecamatan Tallo Kota Makassar. Jenis penelitian ini Studi dengan pendekatan deskriptif dengan menganalisis tentang gambaran kondisi pemukiman dengan penerapan program STBM dengan populasi Jumlah 252 KK dan yang dijadikan sampel sebanyak 155 KK. Hasil penelitian akses kepemilikan Jamban yaitu hampir seluruh warga sudah BAB di Jamban dan melaksanakan program STBM pilar 1 Stop BABS yaitu $141 \mathrm{KK}$ presentase $91 \%$. kepemilikan sarana sanitasi Program STBM sebanyak 93 KK presentase $60 \%$, Numpang 35 KK presentase $23 \%$, sarana Umum 27 KK presentase $17 \%$.Milik pribadi sebanyak 60 \%. Cemplung 1 unit 15 KK sebanyak $9 \%$ dan Leher Angsa 139 unit 139 KK sebanyak $90 \%$. Kondisi sarana Baik $13 \%$ dan $54 \%$ masih kurang dan tidak BAB di Jamban 61 KK $39 \%$, dan bertambah 93 KK $60 \%$, sudah $99 \%$ tidak BAB sembarang tempat.menderita Diare $45 \mathrm{KK} 29 \%$, tidak diare $110 \mathrm{KK}$ atau sebanyak $71 \%$. Kesimpulan dalam penelitian ini adalah $99 \%$ warga sudah tidak BAB sembarang tempat walaupun belum 100\% ODF, namun tingkat penderita Diare Menurun dan untuk penerapan Pilar pertama STBM yaitu Stop BABS dinyatakan bahwa ada perubahan kondisi akses sanitasi Serta adapun hambatan yaitu perlunya peningkatan Tingkat pengetahuan masyarakat tentang program STBM khususnya tentang pilar 1 Stop BABS.

Kata kunci : STBM, Stop BABS, ODF.

\section{PENDAHULUAN}

Program STBM tergolong program yang baru dilaksanakan tidak adanya subsidi pada program ini merupakan tantangan bagi tenaga kesehatan. Program ini lebih menekankan pada perubahan perilaku kelompok masyarakat dengan metode pemicuan. Pemicuan dilaksanakan dengan cara fasilitas kepada masyarakat dalam memperbaiki keadaan sanitasi dilingkungan mereka hingga mencapai kondisi Open Defecation Free (ODF) ditandai dengan $100 \%$ dari buang air besar disembarang tempat. (Dirjen P2PL, 2013).
Permenkes No.3 Tahun 2014 Menyatakan bahwa Sanitasi Total Berbasis Masyarakat (STBM), yang dimaksud dengan STBM adalah pendekatan untuk mengubah perilaku higienis dan sanitasi melalui pemberdayaan masyarakat dengan cara pemicuan. Penyelenggaraan STBM bertujuan untuk mewujudkan perilaku yang higienis dan saniter secara mandiri dalam rangka meningkatkan derajat kesehatan masyarakat yang setinggi-tingginya.

Berdasarkan Data Tentang Capaian nasional STBM tahun 2016 adalah 42,24\% meningkat dari rata-rata capaian tahun 2015 
Jurnal Sulolipu : Media Komunikasi Sivitas Akademika dan Masyarakat

Vol. 19 No.12019

e-issn : 2622-6960, p-issn : 0854-624X

yaitu $32,91 \%$. Provinsi dengan persentase desa/kelurahan yang melaksanakan STBM tertinggi adalah DI Yogyakarta (96,35\%), Nusa Tenggara Barat $(95,07 \%)$, dan Kep. Bangka Belitung (80,62\%). Sedangkan provinsi dengan persentase desa/kelurahan yang melaksanakan STBM terendah adalah Papua (7,05\%), Sulawesi Utara $(7,88 \%)$ dan DKI Jakarta $(9,74 \%)$. Dilihat dari jumlah, 5 (lima) provinsi dengan realisasi desa/kelurahan yang melaksanakan STBM tertinggi yaitu Jawa Timur (5.797 desa/kelurahan), Jawa Tengah (5.222 desa/kelurahan), Jawa Barat (2.401 desa/kelurahan), Nusa Tenggara Timur (2.230 desa/kelurahan), dan Sulawesi Selatan (1.570 desa/kelurahan).

Berdasarkan Profil Dinas Kesehatan Provinsi Sulawesi selatan tahun 2015 dinyatakan Bahwa jumlah desa yang melaksanakan STBM adalah 2.030 dengan prsentase $64.75 \%$ dan desa yang sudah dinyatakan Stop BABS adalah 567 Desa , Dengan presentase $18.09 \%$.

Berdasarkan Data Puskesmas Jumpandang Baru Tentang Penerapan STBM di Lima Kelurahan, dinyatakan jumlah penduduk yang Buang Air Besar Sembarangan (BABS) masih sebesar 13.265 jiwa $(30,40 \%)$, jumlah KK yang memiliki sarana cuci tangan tidak memenuhi syarat sebanyak $3.629 \mathrm{KK}(28,44 \%)$, jumlah KK belum akses sarana air bersih sebanyak 1.831 KK (14,35\%), jumlah KK yang melaksanakan pengelolaan sampah tidak memenuhi syarat sebanyak 5.227 KK (40,96\%), dan jumlah rumah yang memiliki SPAL belum memenuhi syarat sebanyak $6.387 \mathrm{KK}(52,54 \%)$. Oleh karena itu, penelitian mengenai hubungan penerapan program Sanitasi Total Berbasis Masyarakat (STBM) dengan kejadian diare di wilayah kerja Puskesmas Jumpandang baru perlu dilakukan. Tujuan dari penelitian ini adalah untuk mengetahui hubungan antara penerapan program Sanitasi Total Berbasis Masyarakat (STBM) dengan kejadian diare di wilayah kerja Puskesmas Jumpandang baru.

\section{BAHAN DAN METODE}

\section{Lokasi Penelitian:}

Lokasi peneletian ini berada di kelurahan Lakkang, kecamatan Tallo, kota Makassar. Berdasarkan hasil survei yang telah dilakukan, Luas daratan di kelurahan Lakkang yaitu sekira 165 hektar. Dihuni oleh 250 an keluarga yang kebanyakan bekerja sebagai petani, petambak dan nelayan.

2. Desain dan Variabel Penelitian Pelaksanaan Sanitasi Total Berbasis Masyarakat (STBM) dengan akan mempermudah upaya meningkatkan akses sanitasi dasar berbasis masyarakat yang lebih baik serta mengubah dan mempertahankan keberlanjutan budaya hidup bersih dan sehat. Pelaksanaan STBM dalam jangka panjang dapat menurunkan angka kesakitan dan kematian yang diakibatkan oleh sanitasi yang kurang baik, dan dapat mendorong tewujudnya masyarakat sehat yang mandiri dan berkeadilan. Perubahan perilaku dalam STBM dilakukan melalui metode Pemicuan yang mendorong perubahan perilaku masyarakat sasaran secara kolektif dan mampu membangun sarana sanitasi secara mandiri sesuai kemampuan. Dan apabila suatu daerah tidak ada lagi masyarakat yang buang air besar sembarangan, maka daerah tersebut dapat dikatakan mencapai kondisi ODF (Open Defecation Free).

Adapun variabel penelitian pada penelitian ini adalah Penerapan STBM pilar 1 (StopBABS), Pencapaian akses STBM pilar 1, dan Hambatan STBM pilar 1 (Stop BABS) dengan kejadian Diare.

\section{Populasi dan Sampel}

Populasi dalam penelitian ini adalah Semua Rumah di wilayah kerja Puskesmas Jumpandang baru di Kelurahan Lakkang daerah Tallo Adalah 252 rumah.

Adapun Jumlah sampel dalam penelitian ini diambil dari sebagian Populasi yang ditentukan dengan menggunakan metode Simple Random Sampling yang diambil secara acak yaitu sebanyak 155 Rumah yang ada di Wilayah Kerja Puskesmas Jumpandang Baru Kelurahan Lakkang.

\section{Pengumpulan data}

Sumber data terdiri dari 2 yaitu data primer yang diambil secara langsung oleh peneliti dan data sekunder yang diperoleh dari sumber lain seperti, profil perusahaan, buku, jurnal, dan karya tulis ilmiah. Pengumpulan data dilakukan dengan menggunakan metode observasi 
Jurnal Sulolipu : Media Komunikasi Sivitas Akademika dan Masyarakat

Vol. 19 No.12019

e-issn : 2622-6960, p-issn : 0854-624X

dan wawancara dengan menggunakan lembar observasi atau kuesioner.

5. Analisa Data (Jika memakai program statistic, tuliskan uji utama apa yang digunakan)

Analisa data dilakukan dengan menggunakan tabel beserta pembahasannya dan disimpulkan dengan menggunakan Microsoft excel, dan Microsoft word.

HASIL

1. Karakteristik Responden

a. Distribusi Reponden Berdasarkan Umur

Tabel 1

Distribusi Umur Responden KK Program STBM Di Kelurahan Lakkang Kecamatan Tallo Kota Makassar Tahun 2018

\begin{tabular}{|c|c|c|c|}
\hline No. & $\begin{array}{l}\text { Tingkat } \\
\text { umur }\end{array}$ & $\begin{array}{c}\text { Jumlah } \\
\text { (KK) }\end{array}$ & $\begin{array}{c}\text { Persentase } \\
(\%)\end{array}$ \\
\hline 1. & $\begin{array}{l}21- \\
30\end{array}$ & 19 & 12 \\
\hline 2. & $\begin{array}{l}31- \\
40\end{array}$ & 45 & 29 \\
\hline 3. & $\begin{array}{l}41- \\
50\end{array}$ & 47 & 30 \\
\hline 4 & $\begin{array}{l}51- \\
60\end{array}$ & 30 & 19 \\
\hline 5. & $\begin{array}{l}61- \\
70\end{array}$ & 13 & 8 \\
\hline 6. & $\begin{array}{l}71- \\
80\end{array}$ & 1 & 2 \\
\hline Jum & & 155 & 100 \\
\hline
\end{tabular}

Berdasarkan Tabel 1 persentase penggolongan umur di Kelurahan Lakkang, dinyatakan penggolongan yang paling tinggi adalah 41-50 dengan persentase $30 \%$ dan penggolongan yang rendah adalah 71-80 dengan persentase 2 . b. Distribusi Reponden Berdasarkan Jenis Kelamin

Tabel 2

Hasil Distribusi Reponden Berdasarkan

Jenis Kelamin di Kelurahan Lakkang

Kec.Tallo Kota Makassar Pada Tahun 2018

No. Jenis Jumlah Persentase

(KK)

\begin{tabular}{llrl}
\hline 1. & Laki-laki & 134 & 86 \\
2. & Perempuan & 21 & 14 \\
\hline & Jumlah & $\mathbf{1 5 5}$ & $\mathbf{1 0 0}$ \\
\hline
\end{tabular}

Sumber : Data Primer

c. Distribusi Reponden Berdasarkan Tingkat Pendidikan

Tabel 5.3

Distribusi Tingkat Pendidikan KK Program STBM Di Kelurahan Lakkang Kecamatan Tallo Kota Makassar Tahun 2018

\begin{tabular}{|c|c|c|c|}
\hline $\begin{array}{l}\mathrm{N} \\
\mathrm{o} .\end{array}$ & $\begin{array}{l}\text { Tingkat } \\
\text { Pendidi } \\
\text { kan }\end{array}$ & $\begin{array}{l}\begin{array}{l}\text { Juml } \\
\text { ah }\end{array} \\
\text { (KK) }\end{array}$ & $\begin{array}{l}\text { Persent } \\
\text { ase } \\
(\%)\end{array}$ \\
\hline 1. & $\begin{array}{l}\text { Tidak } \\
\text { sekolah }\end{array}$ & 21 & 13 \\
\hline 2. & SD & 40 & 26 \\
\hline 3. & $\begin{array}{l}\text { SMP } \\
\text { SMA - }\end{array}$ & 39 & 25 \\
\hline 4. & $\begin{array}{l}\text { sederaja } \\
t\end{array}$ & 46 & 30 \\
\hline 5. & $\begin{array}{l}\text { Sarjana } \\
\text { (S1) }\end{array}$ & 9 & 6 \\
\hline & Jumlah & 155 & 100 \\
\hline
\end{tabular}

Sumber : Data Primer 
Jurnal Sulolipu : Media Komunikasi Sivitas Akademika dan Masyarakat

Vol. 19 No.12019

e-issn : 2622-6960, p-issn : 0854-624X

\section{d. Distribusi Reponden Berdasarkan Pekerjaan}

Tabel 4

Distribusi Tingkat Pekerjaan KK Pasca

Program STBM Di Kelurahan Lakkang

Kecamatan Tallo Kota Makassar Tahun 2018

\begin{tabular}{cccc}
\hline No. & $\begin{array}{c}\text { Tingkat } \\
\text { Pekerjaan }\end{array}$ & $\begin{array}{c}\text { Jumlah } \\
(\mathrm{KK})\end{array}$ & $\begin{array}{c}\text { Persentase } \\
(\%)\end{array}$ \\
\hline 1. & $\begin{array}{c}\text { Ibu Rumah } \\
\text { Tangga } \\
\text { (IRT) }\end{array}$ & 8 & 5 \\
2. & Tambak & 23 & 15 \\
3. & Wiraswasta & 37 & 24 \\
4. & Petani & 38 & 25 \\
5. & PNS & 10 & 6 \\
6. & Karyawan & 3 & 2 \\
7. & Buruh & 3 & 2 \\
8. & Nelayan & 15 & 9 \\
9. & Wirausaha & 6 & 4 \\
10. & Pedagang & 5 & 3 \\
11. & Tidak & 7 & 5 \\
\hline & Bekerja & 7 & 100 \\
\hline
\end{tabular}

Sumber : Data Primer

2. Tingkat Pengetahuan Responden tentang Program STBM

\section{Tabel 5}

Distribusi Tingkat Pengetahuan KK Tentang Program STBM Pilar 1 Stop BABS (Stop Buang Air Besar Sembarangan)

\begin{tabular}{|c|c|c|c|}
\hline \multirow[b]{2}{*}{ No. } & \multirow[b]{2}{*}{ Kriteria } & \multicolumn{2}{|c|}{ Pengetahuan Program } \\
\hline & & $\begin{array}{r}\text { Jumlah } \\
\text { (KK) }\end{array}$ & $\begin{array}{c}\text { Persentase } \\
(\%)\end{array}$ \\
\hline 1. & Tahu & 73 & 47 \\
\hline 2. & $\begin{array}{l}\text { Ragu- } \\
\text { ragu }\end{array}$ & 20 & 13 \\
\hline 3. & $\begin{array}{l}\text { Tidak } \\
\text { Tahu }\end{array}$ & 62 & 40 \\
\hline & Imlah & 155 & 100 \\
\hline
\end{tabular}

3. Akses Jamban Keluarga

Tabel 6

Distribusi Akses Sarana Jamban Keluarga di Kelurahan Lakkang Kec.Tallo Kota

Makassar

\begin{tabular}{|c|c|c|c|}
\hline \multirow[b]{2}{*}{ No } & \multirow[b]{2}{*}{ Kriteria } & \multicolumn{2}{|c|}{$\begin{array}{c}\text { Buang Air Besar di } \\
\text { Jamban }\end{array}$} \\
\hline & & $\begin{array}{r}\text { Jumlah } \\
\text { (KK) }\end{array}$ & $\begin{array}{c}\begin{array}{l}\text { Persen } \\
\text { tase }\end{array} \\
(\%)\end{array}$ \\
\hline 1. & YA & 141 & 91 \\
\hline 2. & $\begin{array}{c}\text { Kadang- } \\
\text { Kadang } \\
\text { Tidak }\end{array}$ & 13 & 8 \\
\hline 3. & $\begin{array}{c}\text { (danau,tam } \\
\text { bak) }\end{array}$ & 1 & 1 \\
\hline & Jumlah & 155 & 100 \\
\hline
\end{tabular}

4. Kepemilikan Sarana Jamban

Tabel 7

Distribusi kepemilikan Sarana Jamban di Kelurahan Lakkang Kec.Tallo Kota Makassar Tahun 2018

\begin{tabular}{|c|c|c|c|}
\hline \multirow{2}{*}{$\begin{array}{c}\text { No } \\
\text {. }\end{array}$} & \multirow{2}{*}{ Kriteria } & \multicolumn{2}{|c|}{$\begin{array}{c}\text { Kepemilikan Sarana } \\
\text { Jamban }\end{array}$} \\
\hline & & $\begin{array}{l}\text { Jumlah } \\
\text { (KK) }\end{array}$ & $\begin{array}{c}\text { Persenta } \\
\text { se (\%) }\end{array}$ \\
\hline 1. & Pribadi & 93 & 60 \\
\hline 2. & $\begin{array}{c}\text { Numpang } \\
\text { (Sharing) }\end{array}$ & 35 & 22 \\
\hline 3. & Umum & 26 & 17 \\
\hline & Jumlah & 154 & 99 \\
\hline
\end{tabular}

Sumber : Data Primer

5. Jenis Jamban yang digunakan Tabel 8

Distribusi Jenis Jamban yang digunakan di Kelurahan Lakkang Kec.Tallo Kota Makassar Tahun 2018

\begin{tabular}{|c|c|c|c|}
\hline No. & $\begin{array}{c}\text { Jenis } \\
\text { Jamban }\end{array}$ & $\begin{array}{c}\text { Jumlah } \\
\text { (KK) }\end{array}$ & $\begin{array}{c}\text { Persenta } \\
\text { se (\%) }\end{array}$ \\
\hline 1. & $\begin{array}{l}\text { Leher } \\
\text { Angsa }\end{array}$ & 139 & 90 \\
\hline 2. & Cemplung & 15 & 9 \\
\hline & Jumlah & 154 & 99 \\
\hline
\end{tabular}

Sumber : Data Primer 
Jurnal Sulolipu : Media Komunikasi Sivitas Akademika dan Masyarakat

Vol. 19 No.12019

e-issn : 2622-6960, p-issn : 0854-624X

6. Kondisi Sarana Jamban

Tabel 9

Distribusi Kondisi Sarana Jamban

Keluarga

Di Kelurahan Lakkang Kec.Tallo Kota Makassar Tahun 2018

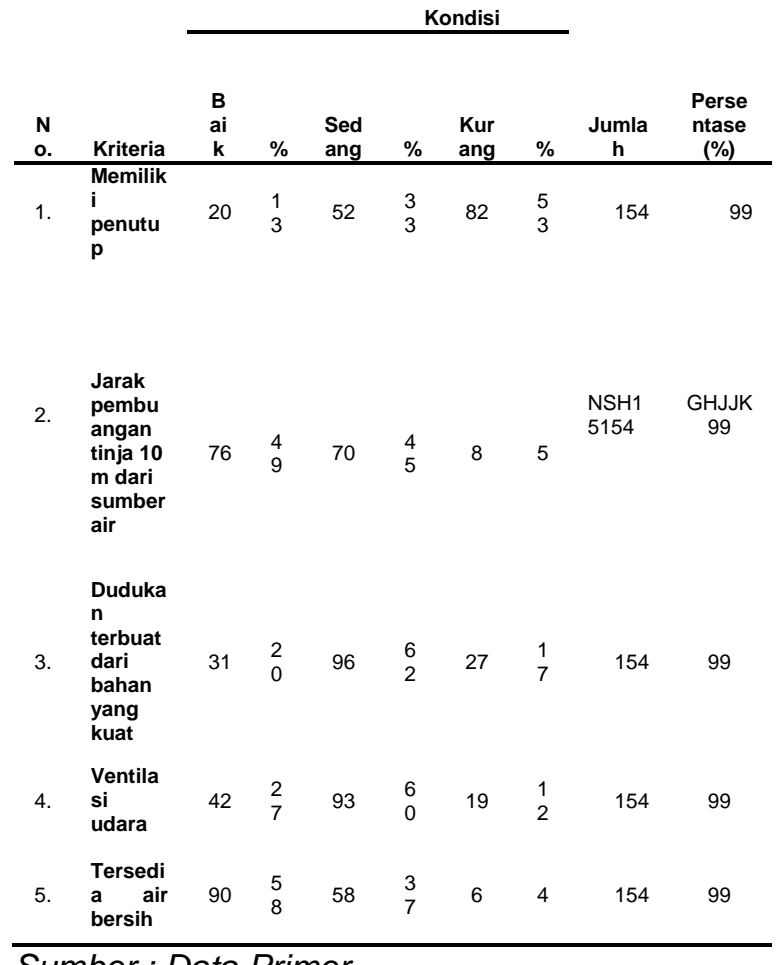

Sumber : Data Primer

7. Perilaku StopBABS Sanitasi Total berbasis Masyarakat (STBM)

Tabel 10

Distribusi Observasi Perilaku STOP-

BABS Sanitasi Total Berbasis Masyarakat (STBM) Di Kelurahan Lakkang Kec.Tallo Kota Makassar Tahun 2018

\begin{tabular}{cccc}
\hline No. & Keterangan & $\begin{array}{c}\text { Jumlah } \\
(\mathrm{KK})\end{array}$ & $\begin{array}{c}\text { Persentase } \\
(\%)\end{array}$ \\
\hline 1. & $\begin{array}{c}\text { Sebelum } \\
\text { STBM } \\
\text { Sesudah } \\
\text { STBM }\end{array}$ & 61 & 39 \\
2. & $\begin{array}{c}\text { Lainnya } \\
\text { (Belum } \\
\text { mengubah } \\
\text { perilaku }\end{array}$ & 93 & 60 \\
& 1 & 1 \\
\hline Jumlah & 155 & 100 \\
\hline Sumber : Data Primer & &
\end{tabular}

\section{Penderita Diare Dalam Kurun Waktu 3 Bulan Terakhir}

Tabel 11

Distribusi Anggota Keluarga Yang Menderita Diare Dalam Kurun Waktu 3 Bulan Terakhir di Kelurahan Lakkang Kec.Tallo Kota Makassar Tahun 2018

\begin{tabular}{lccc}
\hline No. & $\begin{array}{l}\text { Krite } \\
\text { ria }\end{array}$ & $\begin{array}{c}\text { Jumlah } \\
\text { (KK) }\end{array}$ & $\begin{array}{c}\text { Persent } \\
\text { ase } \\
(\%)\end{array}$ \\
\hline 1. & YA & 45 & 29 \\
2. & $\begin{array}{l}\text { Tida } \\
\text { k }\end{array}$ & 110 & 71 \\
\hline & Jumlah & 155 & 100 \\
\hline \multicolumn{4}{c}{ Sumber : Data Primer }
\end{tabular}

\section{Pembahasan}

Berdasarkan dari hasil perhitungan menerangkan bahwa penerapan Sanitasi Total Berbasis Masyarakat (STBM) pilar 1 Stop Buang Air Besar Sembarangan (SBABS) dengan Kejadian Diare di Kelurahan Lakkang Kec.Tallo Kota Makassar dilihat dari perilaku masyarakat mencapai $91 \%$ ini menunjukan tingkat kesadaran masyarakat terhadap program STBM, sedangkan tingkat kepemilikan sarana dan prasarana mencapai $60 \%$, tingkat pengetahuan masyarakat dalam hal penerapan program STBM mencapai $47 \%$.

1. Capaian Akses terhadap Jamban keluarga

Berdasarkan hasil penelitian kepemilikan sarana (jamban) dimana jumlah kepemilikan di Kelurahan Lakkang Kec.Tallo terpenuhi dari jamban. Jamban sehat yang digunakan masyarakat di Lakkang adalah jamban model leher angsa dan cemplung, Jamban cemplung adalah jamban yang tempat penampungan tinjanya dibangun dibawah tempat injakan atau di bawah bangunan langsung ke pejamu yang baru. Jenis jamban ini, kotoran langsung bau. Fungsi dari lubang adalah mengisolasi tinja sedemikian rupa sehingga tidak di mungkinkan penyebaran dari bakteri masuk ke jamban dan tidak terlalu lama karena tidak terlalu dalam karena akan mengotori 
air tanah, kedalamannya 1,5-3 meter dan Jamban leher angsa adalah jamban leher lubang closet berbentuk lengkung, dengan demikian akan terisi air gunanya sebagai sumbat sehingga dapat mencegah bau busuk serta masuknya binatang-binatang kecil. Jamban model ini adalah model yang terbaik yang dianjurkan dalam kesehatan lingkungan. Secara Kontruksi juga memiliki persyaratan agar tetap berfungsi dan tidak menimbulkan permasalahan lain dari penerapannya berdasarkan data hasil penelitian dinyatakan bahwa secara kontruksi jamban di Lakkang sudah memenuhi syarat berdasarkan kriteria obkjektif penelitian dan adapun persyaratan Jamban keluarga yang sehat yang memenuhi syarat-syarat sebagai berikut (Depkes RI, 2004).

a. Tidak mencemari sumber air minum, letak lubang penampung berjarak 10-15 meter dari sumber air minum.

b. Tidak berbau dan tinja tidak dapat di jamah oleh serangga maupun tikus.

c. Cukup luas dan landai/miring ke arah lubang jongkok sehingga tidak mencemari tanah sekitar.

d. Mudah di bersihkan dan aman penggunannya.

e. Dilengkapi dinding dan atap pelindung, dinding kedap air dan warna.

f. Cukup penerang

g. Lantai kedap air

h. Ventilasi cukup baik

i. Tersedia air dan alat pembersih

Berdasarkan data yang telah didapatkan dinyatakan bahwa di Kelurahan Lakkang Kec.Tallo Kota Makassar sebagian besar memiliki mata pencarian sebagai petani yaitu $38 \mathrm{KK}$ hal ini tentunya memiliki pengaruh terhadap penerapan program STBM dan tingkat akses dan kepemilikan sarana.

Berdasarkan data diatas dapat di kaitkan dengan akses dan kepemilikan sarana hal tersebut dinyatakan memiliki pengaruh, karena dalam mengupayakan ketersediaan sarana yang tentunya memerlukan biaya, program STBM adalah program yang sifatnya non anggaran atau non subsidi sehingga sangat penting pengaruh tingkat penghasilan karena walaupun masyarakat memilki tingkat pengetahuan yang baik mereka juga tidak bisa membangun sarana sanitasi.

Berdasarkan Tabel 5.6 Distribusi Akses Sarana Jamban Keluarga di kelurahan Lakkang, hampir seluruh warga sudah Buang Air Besar di jamban dan melaksanakan program STBM pilar 1 Stop BABS yaitu sebanyak $141 \mathrm{KK}$ dengan presentase $91 \%$. Jadi, Hampir seluruh warga di daerah Lakkang sudah memiliki kesadaran akan pentingnya menjaga kesehatan dan lingkungan dengan tidak BAB sembarang tempat dan menerapkan Stop Buang Air Besar Sembarangan (Stop BABS) dan berdasarkan tabel 5.7 tentang kepemilikan sarana jamban dinyatakan bahwa kepemilikan sarana sanitasi Program STBM di Kelurahan Lakkang yaitu kepemilikan pribadi sebanyak $93 \mathrm{KK}$ atau dengan presentase $60 \%$, Numpang $35 \mathrm{KK}$ dengan presentase $22 \%$, dan yang masih menggunakan sarana umum sebanyak 26 KK presentase $17 \%$.

Berdasarkan Kriteria Objektif Penelitian hal tersebut dinyatakan memenuhi standar nilai yang ditetapkan berdasarkan nilai kuisioner yang digunakan dengan indikator menggunakan Skala Likert menurut Budiaji W (2013). Hal tersebut dinilai sudah Baik karena sampel penelitian dinyatakan $91 \%$ masyarakat yang telah memiliki Akses sarana sanitasi khususnya jamban baik Milik Pribadi, Numpang (Sharing), maupun Umum.

Hal ini tidak sejalan dengan penelitian yang dilakukan Leny Setyawati (2012) hasil penelitian menunjukkan evaluasi program sanitasi total berbasis masyarakat di desa Bungin Kecamatan Tinangkung Kabupaten Banggai Kepulauan Provinsi Sulawesi Tengah tahun 2012 tidak berhasil dengan persentase evaluasi program STBM pada kepemilikan jamban $(47,1 \%)$ dan evaluasi program STBM pada pemanfaatan $(47,1 \%)$ serta cakupan jamban $(35,1 \%)$. Diharapkan masyarakat lebih aktif berpartisipasi dan mendukung program sanitasi total berbasis masyarakat serta memiliki dan menggunakan jamban keluarga.

Sejalan dengan penelitian yang dilakukan oleh Agus Erwin Ashari, dkk (2016), didapatkan data cakupan jamban keluarga yaitu cakupan tertinggi pada Puskesmas Binanga 83,64\% dan terendah 
pada Puskesmas Bambu 38,09\%, jika dibandingkan renstra Kemenkes 2010 2014 targetnya adalah 75\%, artinya masih ada puskesmas yang pencapaiannya masih dibawah target yang telah ditetapkan, hal ini sebabkan masih kurang frekuensi pemicuan dan masih rendahnya kesadaran masyarakat. Sejalan dengan penelitian yang dilakukan oleh Darsana, dkk (2014) ada hubungan yang bermakna antara petugas kesehatan, pengetahuan dan sikap dengan kepemilikan jamban.

\section{Keberhasilan program STBM di Lakkang Kec.Tallo}

Berdasarkan hasil penelitian di Kelurahan Lakkang sudah sadar akan pentingnya kesehatan tentang lingkungan khususnya program STBM Pilar 1 Stop BABS. Hal ini dapat dilihat dari capaian akses dan kepimilikan sarana, baik kesadaran masyarakat akan pentingnya kesehatan.

Berdasarkan tabel 5.10 Tentang perilaku Stop BABS dinyatakan bahwa Masyarakat yang Menerapkan Sebelum STBM adalah $61 \mathrm{KK}$ dengan presentase $39 \%$ sedangkan sesudah STBM bertambah menjadi $93 \mathrm{KK}$ dengan presentase $60 \%$.

Berdasarkan data tersebut maka dapat diartikan bahwa sebagian masyarakat Lakkang sudah memiliki tingkat kesadaran akan pentingnya akses sanitasi bagi masyarakat, hal ini tentu dapat diberikan gambaran dari 155 KK sampel yang di teliti dinyatakan $91 \%$ yang telah memiliki akses jamban keluarga, baik yang sebelum pelaksanaan program STBM maupun sesudah program STBM.

$$
\text { Beradasrkan Kriteria Objektif }
$$

penelitian hal tersebut dinyatakan memenuhi standar nilai yang ditetapkan berdasarkan nilai kuisioner yang digunakan dengan menggunakan indikator menggunakan Skala Likert menurut Budiaji W (2013). Perlu adanya pembinaan dan monitoring kondisi oleh instansi terkait guna meningkatkan atau mempertahankan kondisi sanitasi faktual di lingkup masyarakat.

Sejalan dengan penelitian yang dilakukan oleh Arum (2016) dinyatakan bahwa pelaksanaan program STBM pilar pertama Stop Buang Air Besar Sembarangan di Dusun Bonto Boddia Desa Lempangang Kecamatan Bajeng Kabupaten Gowa dari 260 rumah, sebanyak $217(83,4 \%)$ rumah yang telah memiliki jamban keluarga, sementara yang belum memiliki JAGA yakni $43(16,6 \%)$ rumah walaupun belum mencapai target $100 \%$.

Program Sanitasi Total Berbasis Masyarakat (STBM) lebih menekankan pada perubahan perilaku kelompok masyarakat yaitu dengan meningkatkan kesadaran masyarakat terhadap lingkungan mereka dengan metode pemicuan, yaitu melalui para tenaga kesehatan atau kader (kelompok anggota dermawan) yang memberikan pemaparan dan sebagai fasilitator. Program STBM mengajak masyarakat untuk menjadi pelaksana sekaligus pengawas proses pelaksanaan program tersebut. Selain itu, masyarakat juga dilibatkan secara langsung dalam menentukan strategi yang tepat dalam pelaksanaan program STBM dengan difasilitasi oleh kader STBM sehingga tujuan yang telah ditetapkan dapat dicapai dengan baik. Sebagai pelaku utama sekaligus sasaran utama dari program STBM, maka seluruh proses pelaksanaan program dilaksanakan sepenuhnya oleh masyarakat itu sendiri. Oleh karena itu, output atau hasil yang didapatkan akan sesuai dengan tujuan awal program sebagai program yang berbasis masyarakat.

\section{Hambatan program STBM di Kelurahan Lakkang}

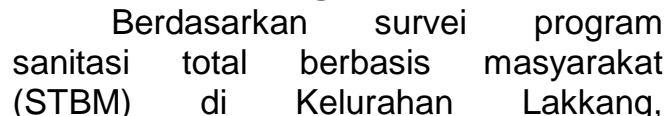
pengetahuan masyarakat khsusnya pilar 1 STBM yaitu StopBABS, Stop Buang Air Besar Sembarangan masih ada $40 \%$ masyarakat yang tidak tahu tentang STBM pilar 1 StopBABS .

Berdasarkan hasil penelitian pada tabel 5.5 dimana pencapaian persentase pada tabel pengetahuan masyarakat di Kelurahan Lakkang dinyatakan yang mengetahui program STBM sebanyak 73 $\mathrm{KK}$ dengan presentase $47 \%$, yang masih ragu-ragu sebanyak $20 \mathrm{KK}$ presentase 
$13 \%$, dan yang tidak tahu sebanyak 62 KK dengan presentase $40 \%$. Hasil pencapaian tersebut masih pada tingkat sedang, hal ini disebabkan karena masih kurangnya upaya sosialisasi mengenai program STBM, hal ini juga memicu tingkat pengetahuan masyarakat tentang membuang air besar sembarangan, menurut tabel 5.5 pengetahuan masyarakat tentang membuang air besar sembarangan, dimana masyarakat yang belum memahami program STBM sebanyak $40 \%$ dan yang ragu-ragu sebanyak $13 \%$.

Sejalan dengan penelitian yang dilakukan oleh Yulis Indriyani (2016), capaian ODF di Kelurahan Tirto belum maksimal. Ada peningkatan perubahan perilaku masyarakat untuk Stop BAB secara sembarangan di Kelurahan Tirto, namun belum 100\% ODF. Perubahan yang demikian dapat dikatakan lamban. Upaya bantuan fisik berupa jamban dari pemerintah kepada masyarakat tidak cukup untuk meningkatkan capaian ODF. Selain itu, pelatihan yang telah diselenggarakan baik secara administratif maupun teknis pun belum dapat berkontribusi pada pencapaian ODF secara signifikan. Penerapan model CLTS (Community Led Total Sanitation) oleh fasilitator STBM dari Puskesmas Tirto untuk pilar 1 STBM juga belum dapat menerobos angka 0\% Stop BAB sembarangan. Terdapat hambatanhambatan terhadap permasalahan di Kelurahan Tirto yang masih menitikberatkan pada pencapaian pilar ODF. Dilihat dari strategi advokasi yang telah dilakukan Kelurahan Tirto terdapat poin yang belum maksimal yaitu komitmen yang konsisten sebagaimana hasil riset terdahulu oleh Sidjabat (2012). Konsistensi komitmen ODF Kelurahan Tirto dapat dipertegas dengan kebijakan yang dituangkan melalui penetapan punisment pada perilaku masyarakat buang air besar sembarangan. Hal itu dapat menjadi peluang tercapainya Kelurahan ODF.

Sosialisasi merupakan tahap awal dari pelaksanaan program STBM agar tujuan program yang telah ditetapkan dapat disampaikan kepada sasaran utamanya yaitu masyarakat. pelaksanaan sosialisasi kepada masyarakat menjadi tantangan tersendiri bagi pihak yang ditunjuk karena inilah penentu apakah program tersebut tersampaikan dengan baik atau tidak.

Hal tersebut ditujukan untuk membina dan mengedukasi masyarakat agar dapat ikut serta dalam program pemerintah untuk menjaga kondisi sanitasi di lingkup Kelurahan Lakkang sebagai salah satu daerah yang berada di daerah yang sulit dijangkau, khususnya tentang Sanitasi Total Berbasis Masyarakat.

Faktor pengetahuan adalah salah satu faktor yang penting untuk mendorong partisipasi dan keterlibatan masyarakat dalam pelaksanaan program STBM, dan menjadi salah satu kunci kesuksesan penyelenggaraan program dengan baik. Program STBM merupakan program yang berbasis masyarakat dan ditujukan kepada masyarakat, oleh karena itu peran masyarakat sangatlah diperlukan.

Selain faktor diatas, adapun hambatan yang dihadapi selama penelitian yaitu pada saat akan melakukan observasi atau men survei rumah di daerah Lakkang, banyak warga yang tidak berada di rumah karena bekerja di luar Pulau mengingat di Kelurahan Lakkang merupakan salah satu Daerah di Kota Makassar yang jika ingin didatangi harus menggunakan transportasi air yang bisa di tempuh sekitar 25-30 menit karena berada di Sungai Tallo. Jadi warga yang bekerja pergi menggunakan transportasi air pagi sekali dan baru pulang pada saat sore hari. Selain itu, masih minimnya frekuensi pemicuan yang dilakukan oleh Puskesmas dan Dinas Kesehatan, dana yang masih terbatas serta respon masyarakat yang masih rendah. Kurang berhasilnya program STBM dari proses pemicuan sampai pasca pemicuan karena masyarakat susah dikumpulkan sehingga proses monitoring dan pemantauan terhambat.

\section{Kejadian Diare Di Kelurahan Lakkang Kec.Tallo Kota Makassar.}

Berdasarkan tabel 5.11 Tentang Distribusi Anggota Keluarga Yang Menderita Diare Dalam Kurun Waktu 3 Bulan Terakhir di Kelurahan Lakkang, masyarakat yang sudah menderita penyakit Diare dalam 
kurun waktu bulan terakhir sebanyak $45 \mathrm{KK}$ atau sebanyak $29 \%$ dan yang tidak menderita penyakit diare $110 \mathrm{KK}$ atau sebanyak $71 \%$. Dari hasil tersebut, dapat dilihat bahwa jumlah warga yang menderita penyakit diare di Kelurahan Lakkang masih dalam tingkat rendah karena jumlah penderita hanya sebanyak $29 \%$ Jika dibandingkan dari tahun sebelumnya dari data Pustu Lakkang penderita 79 atau sekitar $51 \%$ tahun 2018 sudah mengalami penurunan

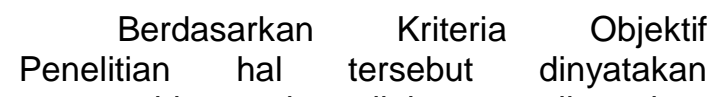
memenuhi standar nilai yang ditetapkan berdasarkan nilai yang digunakan dengan indikator menggunakan Skala Likert Budiaji W (2013). Adapun warga yang menderita penyakit diare jika dilihat dari penerapan STBM khususnya pilar 1, Stop Buang Air Besar Sembarangan yang $91 \%$ warga di Daerah Lakkang sudah buang air besar di jamban yang artinya sudah baik. Namun kejadian diare ini diakibatkan bisa jadi diakibatkan faktor lain. Dari hasil survey yang dilakukan di Lakkang tentang cuci tangan setelah $\mathrm{BAB}$, masyarakat yang selalu mencuci tangan setelah $B A B$ sebanyak $93 \%$, kadang-kadang $10 \%$, dan tidak $1 \%$ Dan Mencuci tangan menggunakan Air dan Sabun sebnyak $66 \%$, Air saja sebnyak $33 \%$, dan lainnya $1 \%$. Dari hasil survey tersebut dapat disimpulkan Bahwa Masyarakat yang menderita penyakit diare tersebut bisa jadi diakibatkan dari perilaku setelah Buang Air Besar.

Dalam hal ini, pentingnya peranan dari petugas pelayanan kesehatan sangat diperlukan untuk memberikan pengetahuan lebih kepada masyarakat akan pentingnya sanitasi untuk kehidupan dan lingkungan terutama pentingnya hygiene perorangan dalam menjaga kesehatan.

\section{PENUTUP}

\section{KESIMPULAN}

a. Penerapan Program STBM di Kelurahan Lakkang Berdasarkan Akses Sarana Jamban Keluarga di kelurahan Lakkang, hampir seluruh warga sudah Buang Air Besar di Jamban dan melaksanakan program STBM pilar 1 Stop BABS dan
Distribusi Anggota Keluarga Yang Menderita Diare Dalam Kurun Waktu 3 Bulan Terakhir di Kelurahan Lakkang, masyarakat yang sudah menderita penyakit Diare dalam kurun waktu 3 bulan terakhir di Daerah Lakkang Masih Dikategorikan Rendah

b. Capaian akses penerapan program STBM Pilar 1 (Stop BABS) terhadap masyarakat di Kelurahan Lakkang Kec.Tallo kota Makassar berdasarkan Perilaku Stop BABS sebelum dan sesudah Program STBM, sudah mencapai $99 \%$ walaupun belum $100 \%$ dikatakan ODF.

c. Hambatan-hambatan program STBM di kelurahan Lakkang adalah tingkat pengetahuan tentang STBM masih rendah, namun penerapannya sudah hampir mencapai $100 \%$.

\section{SARAN}

a. Kepada petugas Pelayanan kesehatan baik Puskesmas dan Pustu yang menangani Kelurahan Lakkang untuk meningkatkan penyuluhan tentang Perilaku Hidup Bersih dan Sehat (PHBS) khususnya Sanitasi Total Berbasis Masyarakat (STBM) Terutama Pilar 1 StopBABS perilaku membuang air besar dan dampaknya terhadap lingkungan.

b. Kepada Petugas Pelayanan Kesehatan, Agar Meningkatkan Pelayanan Kesehatan terhadap Masyarakat yang ada di Kelurahan Lakkang Karna Sulitnya Akses Transportasi disana ke Puskesmas

c. Kepada Pemerintah agar memberikan Perhatian Terhadap Daerah yang sulit dijangkau seperti Daerah Lakkang tersebut. Untuk meningkatkan Sarana dan Prasarana di daerah tersebut. Seperti yang kita ketahui Daerah Lakkang juga Memiliki potensi Pariwisata. 
Jurnal Sulolipu : Media Komunikasi Sivitas Akademika dan Masyarakat

Vol. 19 No.12019

e-issn : 2622-6960, p-issn : 0854-624X

\section{DAFTAR PUSTAKA}

Aditama Tjandra Yoga. 2014. Pedoman Implementasi Ppsp Melalui Penguatan Pilar- Pilar Stbm (Ipp-Stbm). Jakarta : POKJA AMPL

Aditama Tjandra Yoga. 2013. Road Map Percepatan Program STBM. (Online) :http://stbmindonesia.org/ . Diakses 22 Desember 2017

Aditama Tjandra Yoga. 2014. Kurikulum Dan Modul Pelatihan Fasilitator Stbm Sanitasi Total Berbasis Masyarakat Di Indonesia. Jakarta: Kementerian Kesehatan RI 2014

Agustina T. 2015. Evaluasi Pelaksanaan Program Sanitasi Total Berbasis Masyarakat Pilar Pertama (Stop BABS) di Wilayah Kerja Puskesmas Pemulutan. Jurnal FKM Universitas Sriwijaya. (online) : http://ejournal.unisri.ac.id/. Diakses 26 November 2017

Ariani Ayu Putri. 2016. Diare (Pencegahan dan Pengobatannya). Yogjakarta : Nuha Medika

Badan Pusat Statistik. 2015. Profil Statistik Kesehatan kota Makassar Tahun 2015. Makassar

Dinar Andaru Mukti, dkk. 2016. Hubungan Antara Penerapan Program SanitasiTotal Berbasis Masyarakat (STBM) Di Wilayah Kerja Puskesmas Jatibogor. Jurnal Kesehatan Masyarakat FKM Universitas Diponegoro. (online) : http://ejournal3.undip.ac.id/. Diakses 26 November 2017.

Dinas Kesehatan Kota Makassar. 2016. Profil Kesehatan Kota Makassar 2015. (Online) : Http://ProfilKesehatanKotaMakassarTahun 2015. Diakses 24 Desember 2017

Falasifa Mila. 2015. Hubungan Antara Sanitasi Total Dengan Kejadian Diare Pada Balita Di Wilayah Kerja Puskesmas Kepil 2 Kecamatan KepilKabupaten Wonosobo Tahun 2015. Jurusan Ilmu Kesehatan Masyarakat.Halaman142.(Online) : http://lib.unnes.ac.id/.Diakses 12 Desember 2017.

Kementerian Kesehatan Republik Indonesia. 2013. Buku Saku Verifikasi Sanitasi Total Berbasis Masyarakat (STBM). Jakarta : Sekretariat STBM

Leni Setyawaty. 2012. Evaluasi Program Sanitasi Total Berbasis Masyarakat Dalam Kepemilikan Jamban Di Desa Bungin Kecamatan Tinangkung Kabupaten Banggai Kepulauan Provinsi Sulawesi Tengah Tahun 2012. Jurnal Kesehatan Masyarakat Universitas Gorontalo (Online) : $\quad$ https://media.neliti.com/. Diakses 27 Juni 2018

Megasari, dkk. 2015. Perilaku Kesehatan Masyarakat Terhadap Kejadian Diare Berdasarkan Aspek Sanitasi Lingkungan Di Kabupaten Barito Kuala. Jurnal Kesehatan Lingkungan Politeknik Kesehatan Kementeriaan Kesehatan Banjarmasin. (Online) : http://ppip.unlam.ac.id/. Diakses 13 Desember 2017.

Moh. Fajar Nugraha. 2015. Dampak Program Sanitasi Total Berbasis Masyarakat (Stbm) Pilar Pertama (Di Desa Gucialit Kecamatan Gucialit Kabupaten Lumajang). Skripsi Thesis Universitas Airlangga. (Skripsi Online) : repository.unair.ac.id/. Diakses 19 Januari 2018 
Jurnal Sulolipu : Media Komunikasi Sivitas Akademika dan Masyarakat

Vol. 19 No.12019

e-issn : 2622-6960, p-issn : 0854-624X

Retno Purwandari, dkk. 2013. Hubungan Antara Perilaku Mencuci Tangan Dengan Insiden Diare Pada Anak Usia Sekolah Di Kabupaten Jember. Jurnal IImu Keperawatan Universitas Jember. (online): $\quad$ http://ejournal.unej.ac.id/. Diakses 26 November 2017

Yulis Indriyani. 2016. Kajian Strategi Promosi Kesehatan Sanitasi Total Berbasis Masyarakat (STBM) Kelurahan Tirto Kecamatan Pekalongan Barat Kota . Pekalongan. Unnes Journal of Public Health. (Online) http://journal.unnes.ac.id/sju/index.php/ujph. Diakses pada tanggal 30 Juni 2018 